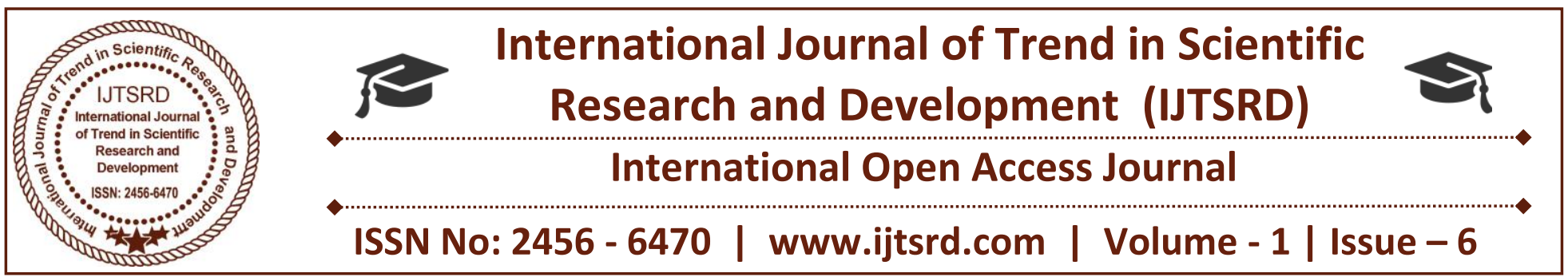

\title{
Bapov Ramazan Salikovich - the Inimitable Principal Dancer of the Kazakh Ballet
}

\author{
Shankibaeva Aliya Bakhitzhanovna \\ Candidate of Art Studies, Professor at T.K. \\ ZhurgenovKazakh National Academy of Arts
}

\author{
Karzhaubayeva Sangul Kamalovna \\ Doctor of Art Studies, Professor at T.K. Zhurgenov \\ Kazakh National Academy of Arts
}

\begin{abstract}
In the article, the authors analyze the work of the great Kazakh dancer RamazanBapov, considering his unique performance through the interpretation of the artistic images of the leading ballet parties. Individual skill of the dancer as a sample of choreographic art is relevant from the point of view of modern analysis of choreography. National scenic images created by the dancer convey the spirit of patriotism and the genetic code of the Kazakh people. The articletells aboutcreative significance of the dancer for the Kazakh choreography
\end{abstract}

Keywords: theatre, choreography, performing arts, national dance, stage image, ballet, scenography

\section{INTRODUTION}

The artistic work of the genius dancer of the world ballet, the unique master of the Kazakh ballet stage, the soloist of the Abai State Academic Opera and Ballet Theatre, the People's Artist of the USSR RamazanSalikovichBapov, impressed with its beauty, admired with the performance technique and with the artistic richness of the main parts of the play.

The more time passes since his performances, the more convex is his unrepeatable creativity. You understand how it was a blessing for our Kazakh ballet art that the unique talent of RamazanBapov found, at the time, a worthy training at the Moscow Academic Choreographic School. It was there, studying in the class of the honored artist of the RSFSR A.M. Rudenko, the teachers of classical dance were able to lay a professional foundation in the unique creativity of the young dancer and create in his soul a great love for the chosen complex profession.

The creative work of RamazanBapov in terms of his talent, close to the lyrical role, was consonant with the modern search for the ballet theatre of the 70s and $80 \mathrm{~s}$. His characters, despite the strict canons of the ballet text, where given a clear technical drawing, had their own personality, their character. His characters thought and lived on stage, enriched by the poetic truth of the image. His characters were different: bold, strong, romantic, funny and tragic, but the whole palette of these characters found their expressive form, which reflected the rich inner world of the most outstanding dancer.

RamazanBapov, as an artist who created his stage images, succeeded in using his individuality to raise his characters over the ordinary, thereby showing their greatness, over which, time does not dominate. Such are his characters: this is the first bright image of Kozy-Korpesh in the ballet "Kozy-Korpeshand Bayan-Sulu,"Romeo in "Romeo and Juliet," James in "Sylphid," Hooligan in "The Lady and the Hooligan," Spartacus in the ballet of the same name. All these images are completely different, but in the performance of the dancer, each of this party reached the highest point of its expression, striking with its fullness of life. For RamazanSalikovich there were no secondary roles. Each new role and even then, repeatedly performing it, he treated with his professional honesty. 
In turn, each reached peak in the interpretation of images, proved his unique acting talent. In playing each of his character, despite all the complicated dance technique, he came up with such thoroughness of performing that any gesture, a turn of the head or body, a glance at the stage, all these details mattered and were full of meaning. The unique creative individuality of R. Bapov, his rich inner world filled the stage characters with such bright colors that were close to his artistic nature. Every action of his characters seemed to be done naturally and simply, obeying his spiritual impulse. Moreover, watching his dance it was clear that the most complicated specific choreographic jumps and pirouettes were the only true solution to the unique language of this character.

The most complicated choreographic crosscuts were brought to perfection by the dancer and made his dance flawless. The technical side of the ballet part, worked out for hours of rehearsals to the smallest parts, left space for the master to work on the actor's imagery. RamazanBapov appeared on the stage as Romeo or Siegfried, Spartacus or Hooligan, as James or Albert. The dancer felt so bright and organ icon stage and unfolded an integral artistic ballet action for the viewer.

All the classical moves of Ramadan Bapov refracted through his own individuality. His dance had beautiful lines, the breadth and completeness of each movement, an unusually high and beautiful jump with a noiseless landing, long rotations. His dancing manner was distinguished by natural nobility, an exact sense of the era and style of the play. Performing recognized world classical ballets, he painted them with his unique handwriting, entering into a galaxy of representatives of the masters of the Bolshoi Ballet as V. Vasiliev, M. Lavrovsky, A. Liepa and others.

However, as a national dancer, he clearly understood this subtle nerve of the role. Such were his characters: Kozy-Korpesh in E. Brusilovsky's ballet "KozyKorpesh and Bayan-Sulu," Basil in L. Minkus's ballet "Don Quixote," Chin-Tomur in K. Kuzhamyarov's ballet "Chin-Tomur," IshpakKhan in T. Mynbayev's ballet "Frescoes" and others.

RamazanSalikovich treated the culture and national dance of his people with great respect. A careful attitude to the national dance as a source of inexhaustible variety of colors was expressed in his performances of masterpieces of Kazakh stage dance, such as E.Brusilovsky's "Balbyraun," Dauletkerei's "Kos-Alka" and others. Presenting Kazakh choreography abroad, and performing one or two national numbers in an obligatory concert program, RamazanSalikovich tried to convey the spirit of folk plastic and did it with great pleasure. Poeticized in the dance movements of the rider's plastic and his horse, as the most stable form of folk plastic culture, preserved for many centuries of its development, and already in our time, performed by a brilliant dancer, acquired a special national identity and pride

These national dances aroused special interest among the foreign viewer by the fact that their content and a certain meaning allowed glimpsing into the inner world of the people, which was represented by the impeccable performance of RamazanBapov. Dance movements, individual plastic elements, different positions and poses, filled with the individual character of the dancer, helped to identify him with the people and thereby understand the national roots of his creative skill and philosophical comprehension of dance art.

Careful about national origins, performing national dances, a brilliant dancer enriched the stage performance, whether in ballet or in a separate dance routing. This feature of plastic expressiveness, this national color was subtly revealed in such ballets as $\mathrm{T}$. Mynbayev's "Frescoes," where RamazanportrayedKhan Ishpak, L. Minkus'sBayaderka (The Temple Dancer) asSolor, "Alia" by M. Sagatovas the young man and others. Through performances of the national ballets, the work of RamazanBapova revealed a unique facet of his talent. National features of the people, such as breadth of character, unrestrained energy, softness in dealing with a partner and firmness in decisionmaking, stiffness towards enemies, all this was refracted by numerous facets in a single execution, revealing the unique talent of the dancer. Especially this color was manifested in the performance of the Khan Ishpakrolein the ballet by $T$. Mynbayev "Frescoes" staged by our outstanding choreographer ZaurGalievichRaibaev. The interesting and unordinary music of the composer T. Mynbayev, the unique decision of E. Sidorkin's scenography, the choreography of $\mathrm{Z}$. Raibaev were at that time a new word, "solving the problem of national and international from the positions of today" [1], ballet art in general and the Kazakh ballet in particular. The ballet "Frescoes" marked a new stage in the 
development of the Kazakh ballet, combining a national theme, solved by modern ballet language. This performance was a landmark in the creative destinies of the choreographer Z. Raibaev and the dancer R. Bapov. This creative tandem embodied the "golden age" of the history of Kazakh choreography, where the choreographer and performer merged into a grateful union, whose professional capabilities allowed to create more than one brilliant performance that is not inferior to the requirements of the world ballet. Thanks to the creative genius of ZaurbekRaibaev and the performing skills of RamazanBapov, the national Kazakh ballet raised its bar to the international level.

RamazanSalikovich amazed with his openness. His class-training, mandatory for all artists of the troupe, has always been open to all those wishing to raise their professional level. His lessons impressed with the simplicity of the composition of each exercise and the important and necessary result that each artist received for further performance. He was never seen as fussy, hurrying, and late for a lesson or rehearsal. He always came in advance and modestly kneaded at the bench. In any of his comments, colleagues felt creative support. He never raised his voice to artists, whether he was a peer or just a beginner dancer. All these traits of character caused deep respect for him and reverence.

Now, with time, comes the understanding that this was an expression of true love and great respect for a profession. RamazanSalikovich, being himself the deepest professional, in every way contributed to the professional growth of the artists of the troupe. This was evident from the general impression of the performances. All those who were close to RamazanSalikovich involuntarily inwardly pulled themselves up, and this was a natural need to match the world scale of our brilliant dancer.

RamazanSalikovichBapov made an invaluable contribution to the development of the ballet theatre in the republic. He raised the bar of Kazakh ballet performance to the world's height, remaining the embodiment of the inspired service to art.

\section{REFERENCES:}

1) Eniseeva L. I ozhilifreski (And the "Frescoes" came to life). "Vechernyaya Alma-Ata" from $11 / 21 / 81$. 